\title{
Whole-plant Carbon Dioxide Exchange Responses of Angelonia angustifolia to Temperature and Irradiance
}

\author{
Amanda M. Miller, Marc W. van Iersel, ${ }^{1}$ and Allan M. Armitage \\ Department of Horticulture, The University of Georgia, Athens, GA 30602-7273
}

\begin{abstract}
Additional INDEX words. photosynthesis, respiration, $\mathrm{Q}_{10}$, quantum yield, light compensation point
Abstract. Light and temperature responses of whole-plant $\mathrm{CO}_{2}$ exchange were determined for two cultivars of Angelonia angustifolia Benth., 'AngelMist Purple Stripe' and 'AngelMist Deep Plum'. Whole crop net photosynthesis $\left(P_{\text {net }}\right)$ of 'AngelMist Purple Stripe' and 'AngelMist Deep Plum' were measured at eight temperatures, ranging from 17 to $42{ }^{\circ} \mathrm{C} . \mathrm{P}_{\text {net }}$ for both cultivars increased from 17 to $\approx 20{ }^{\circ} \mathrm{C}$, and then decreased as temperature increased further. Optimal temperatures for $P_{\text {net }}$ of 'AngelMist Purple Stripe' and 'AngelMist Deep Plum' were 20.8 and $19.8{ }^{\circ} \mathrm{C}$, respectively. There was no significant difference between the two cultivars, irrespective of temperature. The $Q_{10}$ (the relative increase with a $10{ }^{\circ} \mathrm{C}$ increase in temperature) for $P_{\text {net }}$ of both cultivars decreased over the entire temperature range. Dark respiration $\left(R_{\text {dark }}\right)$ of both cultivars showed a similar linear increase as temperature increased. As photosynthetic photon flux $(P P F)$ increased from 0 to 600 $\mu \mathrm{mol} \cdot \mathrm{m}^{-2} \cdot \mathrm{s}^{-1}, \mathbf{P}_{\text {net }}$ of both cultivars increased. Light saturation was not yet reached at $600 \mu \mathrm{mol} \cdot \mathrm{m}^{-2} \cdot \mathrm{s}^{-1}$. The light compensation point occurred at $69 \mu \mathrm{mol} \cdot \mathrm{m}^{-2} \cdot \mathrm{s}^{-1}$ for 'AngelMist Purple Stripe' and at $89 \mu \mathrm{mol} \cdot \mathrm{m}^{-2} \cdot \mathrm{s}^{-1}$ for 'AngelMist Deep Plum'. The lower light saturation point of 'AngelMist Purple Stripe' was the result of a higher quantum yield $\left(0.037 \mathrm{~mol}^{\circ} \mathrm{mol}^{-1}\right.$ for 'AngelMist Purple Stripe' and $0.026 \mathrm{~mol} \cdot \mathrm{mol}^{-1}$ for 'AngelMist Deep Plum'). The difference in quantum yield between the two cultivars may explain the faster growth habit of 'AngelMist Purple Stripe'.
\end{abstract}

In recent years, consumer interest in new ornamental crops has increased, due partly to new crop discovery and introduction, and partly to overuse of standard plant materials. Many new ornamental plants have been introduced into the United States during the last 10 to 20 years. Most of these species have originated in other regions of the world, and show heavy influence from European floriculture (Lawson and Roh, 1995). Development and introduction of new crops remains of great interest, especially when they fit existing or rising trends of consumer interest (Noordegraaf, 1998). Data on optimal production conditions for these new crops often is lacking. Carbon dioxide exchange measurements can be used to determine how these crops respond to different environmental conditions, such as light levels and temperatures. Light and temperature effects on $\mathrm{CO}_{2}$ exchange rate of plants can be determined relatively quickly. This type of information can be used to determine the temperatures for maximum photosynthetic rates, required light levels for good growth, and allow for comparison with other plants that can be grown in similar environments.

Measuring photosynthesis is usually done on single leaves, but single leaf measurements may not be representative of the whole plant (van Iersel and Bugbee, 2000). Thus, single-leaf measurements often are poorly correlated with dry matter production (Elmore, 1980; Evans, 1993). However, by measuring photosynthesis of whole plants more accurate measurements of growth can be made (e.g., Long et al., 1996; Ranney and Ruter, 1997; van Iersel and Lindstrom, 1999). For this reason, whole-canopy $\mathrm{CO}_{2}$ exchange measurements are becoming more common in determining precise information about environmental effects on plant growth. By measuring the $\mathrm{CO}_{2}$ exchange rate (a measure of growth) of multiple

Received for publication 13 Aug. 2000. Accepted for publication 17 June 2001. We thank Keven Calhoun and Larry Freeman for technical assistance. Mention of brand names is for informational purposes only and does not imply its approval to the exclusion of other products that may also be suitable. The cost of publishing this paper was defrayed in part by the payment of page charges. Under postal regulations, this paper therefore must be hereby marked advertisement solely to indicate this fact.

${ }^{1}$ Corresponding author. Mailing address: Department of Horticulture, 1109 Experiment Street, Griffin, GA 30223-1797. E-mail: mvanier@gaes.griffin. peachnet.edu. whole plants together, experimental error can be decreased (van Iersel and Bugbee, 2000). Carbon dioxide exchange rates of multiple groups of plants or canopies can be measured using a fully automated system, which can operate unattended (van Iersel and Bugbee, 2000). Since these data can be collected in growth chambers, this technique has made it much simpler to determine whole plant $\mathrm{CO}_{2}$ exchange responses to environmental conditions.

Little is known about gas exchange or growth requirements of angelonia (Angelonia angustifolia) because it is a relatively new crop to the floriculture industry. Therefore, the objective of this research was quantify how whole-plant $\mathrm{CO}_{2}$ exchange rates of two angelonia cultivars respond to different temperatures and light levels.

\section{Materials and Methods}

Plant material. Rooted stem cuttings of 'AngelMist Purple Stripe' and 'AngelMist Deep Plum' angelonia were received and transplanted into 10-cm-diameter pots on 15 Dec. 1999 and grown in a glass-covered greenhouse. The cuttings were transplanted into a commercial soilless medium (Fafard 6-M; Fafard Co., Anderson, S.C.) and were pinched to three nodes 1 week after transplanting. The plants were then allowed to grow until 10 Feb. 2000 when the gas exchange studies were started. Average greenhouse temperatures were 20 to $23^{\circ} \mathrm{C}$ and no supplemental light was supplied while the plants were grown. Pots were fertigated with constant liquid feed at $200 \mathrm{mg} \cdot \mathrm{L}^{-1} \mathrm{~N}$ provided by a $15 \mathrm{~N}-0 \mathrm{P}-12.4 \mathrm{~K}$ water soluble fertilizer (Peters Dark Weather Feed, The Scotts Co., Marysville, Ohio) as needed. The pots were leached every fifth irrigation to prevent soluble salts accumulation.

$\mathrm{CO}_{2}$ EXCHANGE MEASUREMENTS. Carbon dioxide exchange data of groups of five angelonia plants were collected using a multichamber, semicontinuous $\mathrm{CO}_{2}$ exchange system (van Iersel and Bugbee, 2000). Ambient air was blown into acrylic gas exchange chambers $\left(3.2 \times 5 \times 6 \mathrm{dm}^{3}\right)$ and airflow into the chambers was measured with mass flow meters (GFM37-32, Aalborg Instruments and Controls, Monsey, N.Y.). The $\mathrm{CO}_{2}$ concentration of the incoming air was measured with an infrared gas analyzer (IRGA) (SBA-1, PPsystems, Haverhill, Mass.). The difference in the $\mathrm{CO}_{2}$ concentration 
of the air entering and exiting the chamber was measured with an IRGA in differential mode (LI-6251, LI-COR, Lincoln, Nebr.). Airflow to the differential IRGA was controlled by opening and closing solenoid valves. The solenoid valves were controlled by a SDM-CD16AC relay module and CR10T data logger (Campbell Sci., Logan, Utah). Whole chamber $\mathrm{CO}_{2}$ exchange (micromoles of $\mathrm{CO}_{2}$ per second) was calculated as the product of mass flow (moles of air per second) and the difference in $\mathrm{CO}_{2}$ concentration of the air entering and exiting the chamber (micromoles of $\mathrm{CO}_{2}$ per mole of air). Every chamber was measured for $30 \mathrm{~s}$, once every $10 \mathrm{~min}$. There was a $30 \mathrm{~s}$ delay in data collection after solenoids were switched to measure the next chamber, to assure that all air from the previous gas exchange chamber was purged from the tubing and IRGA. Within a 30 s measuring period, 15 data points were collected which normally varied by $<5 \%$. These 15 data points were collected and averaged automatically, and the average was stored by the datalogger.

Five plants of a cultivar were enclosed in each acrylic gas exchange chamber and eight chambers were placed into two larger growth chambers (model E-15; Conviron, Asheville, N.C.), so each growth chamber contained four gas exchange chambers. Errors in the measurements due to zero drift of the differential IRGA were corrected by subtracting the $\mathrm{CO}_{2}$ exchange rates of empty gas exchange chambers from the measured $\mathrm{CO}_{2}$ exchange rate of the plants. Temperature in the gas exchange chambers was measured with shielded, aspirated, type $\mathrm{T}$ thermocouples connected to a thermocouple multiplexer (model AM25T; Campbell Sci.).

Since whole plants, including the containers, were enclosed in the gas exchange chambers, $\mathrm{CO}_{2}$ exchange rates include root and growing medium (from decomposition of organic materials and microbial metabolism) respiration. Since root respiration is part of the whole-plant metabolism, this should be included in whole-plant $\mathrm{CO}_{2}$ exchange measurements. Respiration by microorganisms in the root zone consists of two separate processes, respiration of organic compounds leaking from plant roots and microbial breakdown of organic matter in the growing medium.

Respiration resulting from breakdown of organic products leaking from plant roots into the soil or growing medium should be included in whole-plant net $\mathrm{CO}_{2}$ exchange measurements. The carbon (C) in these compounds was originally fixed in the photosynthetic process, but they are no longer available for plant growth after they leak from the roots. This leakage represents a net loss of $\mathrm{C}$ from the plants, and thus has to be accounted for in whole-plant $\mathrm{C}$ exchange measurements. Regardless, Smart et al. (1995) have estimated that the contribution of rhizoplane microbes to total root zone respiration is small $(<1 \%$ in nonstressed plants and probably a small percentage under stressful conditions) and thus would not have a significant effect on whole plant $\mathrm{CO}_{2}$ exchange. Respiration resulting from microbial breakdown of organic matter in soilless growing media would induce errors in estimates of the whole plant $\mathrm{C}$ balance, but normally is negligible compared to plant $\mathrm{CO}_{2}$ exchange rates (van Iersel and Bugbee, 2000).

Temperature ReSPOnSE CURVES. Four gas exchange chambers, within the same growth chamber, were used to determine $\mathrm{P}_{\text {net }}{ }^{-}$ temperature response curves. To measure whole plant $\mathrm{P}_{\text {net }}$ across a temperature range, the growth chamber was programmed for eight different temperatures $\left(9\right.$ to $\left.40{ }^{\circ} \mathrm{C}\right)$. The temperature series was started immediately after the plants were placed in the chamber and every temperature was maintained for $3 \mathrm{~h}$, so a complete temperature series lasted $24 \mathrm{~h}$.. Temperature inside the gas exchange chambers was higher than that in the growth chamber, because of heat output from the incandescent and fluorescent lamps and ranged from 17 to $42{ }^{\circ} \mathrm{C}$. Photosynthetic photon flux (PPF) was 440 $\mu \mathrm{mol} \cdot \mathrm{m}^{-2} \cdot \mathrm{s}^{-1}$ at the top of the plant canopies. Relative humidity in the gas exchange chambers was measured with humidity probes (HTO45R, Rotronic, Huntington, N.Y.), and decreased from $76 \%$ to $41 \%$ with increasing temperature. No attempt was made to maintain a constant vapor pressure deficit at the different measurement temperatures, because vapor pressure deficit normally increases with increasing temperature under natural conditions. Thus, by not controlling the vapor pressure deficit, more realistic data on effects of increasing temperature on plant $\mathrm{CO}_{2}$ exchange and growth were obtained. Carbon dioxide concentrations in the gas exchange chambers ranged from $300\left(\right.$ at $23^{\circ} \mathrm{C}$ ) to $360 \mu \mathrm{mol} \cdot \mathrm{mol}^{-1}$ (at $42^{\circ} \mathrm{C}$ ) during the $\mathrm{P}_{\text {net }}$ measurements.

Whole-plant $\mathrm{R}_{\text {dark }}$ of four groups of plants was measured in a second growth chamber during the same 24-h period using the second set of four gas exchange chambers. This growth chamber was programmed to increase the temperature from 12 to $40^{\circ} \mathrm{C}$ in 4 ${ }^{\circ} \mathrm{C}$ steps. Without radiative heating by the lamps, temperatures inside the gas exchange chambers were close to the growth chamber set points. Relative humidity during the dark respiration $\left(\mathrm{R}_{\text {dark }}\right)$ measurements ranged from $57 \%$ to $72 \%$ and $\mathrm{CO}_{2}$ concentrations were between 400 (at $13{ }^{\circ} \mathrm{C}$ ) and $435 \mu \mathrm{mol} \cdot \mathrm{mol}^{-1}$ (at $39^{\circ} \mathrm{C}$ ).

LIGHT RESPONSE CURVES. The following day, the same plants from the temperature response curves were used to determine $\mathrm{P}_{\text {net }}{ }^{-}$ light response curves. The plants were left in the chambers, and air temperature was kept constant at $25{ }^{\circ} \mathrm{C}$. The plants were then subjected to increasing $P P F$, starting at 0 and increasing to 600 $\mu \mathrm{mol} \cdot \mathrm{m}^{-2} \cdot \mathrm{s}^{-1} . \mathrm{P}_{\text {net }}$ measurements were collected after $\mathrm{P}_{\text {net }}$ of the plants had stabilized at each $P P F$ level, which took approximately 30 min. The 11 different $P P F$ levels used to measure $\mathrm{P}_{\text {net }}$ were approximately $0,40,110,140,225,280,350,410,450,550$, and 600 $\mu \mathrm{mol} \cdot \mathrm{m}^{-2} \cdot \mathrm{s}^{-1} \cdot \mathrm{P}_{\text {net }}$ may have been affected by feedback inhibition during these measurements, , but this effect was probably small since lightirradiances in this study were relatively low $\left(\leq 600 \mu \mathrm{mol} \cdot \mathrm{m}^{-2} \cdot \mathrm{s}^{-1}\right)$ and angelonia is a crop that tolerates high irradiances well (unpublished results of the authors).

Leaf areas were measured immediately after the conclusion of the $\mathrm{P}_{\text {net }}$-light response curves using an area meter (LI-3100; LICOR) and were $675 \pm 36$ and $664 \pm 27 \mathrm{~cm}^{2}$ for 'AngelMist Deep Plum and 'AngelMist Purple Stripe', respectively (values are means \pm SE of the total leaf area of five plants in each chamber, $n=4)$. To correct for differences in plant size among the groups of plants, $\mathrm{CO}_{2}$ exchange rate of the plants was calculated both per five plants (one gas exchange chamber) and per unit leaf area. Whole plant data have the advantage that they are better indicators of plant growth, while data expressed per unit leaf area are easier to compare with most published photosynthesis research, since most researchers measure leaf $\mathrm{P}_{\text {net }}$.

DATA ANALYSIS. To allow the temperature and $\mathrm{CO}_{2}$ exchange rate of the plants in the gas exchange chambers to stabilize after changing the growth chamber temperature, the first $2 \mathrm{~h}$ of data at a specific temperature were not used for further analysis. Temperature response curves were constructed by averaging the data from the last hour of measurements at every temperature.

Photosynthetic responses to temperature were analyzed using cubic regression, which in all cases was significant at $P<0.001\left(R^{2}\right.$ $>0.98$ ). Optimal temperature for $\mathrm{P}_{\text {net }}$ was determined as the temperature at which these cubic regression curves predicted the highest $P_{\text {net }}$. The optimal temperature range was defined as the temperature at which $\mathrm{P}_{\text {net }}$ was at least $95 \%$ of the maximum $\mathrm{P}_{\text {net }}$, as predicted by the regression curves. Dark respiration responses to temperature were analyzed with linear regression which was significant at $P<0.001$, 
$\left(R^{2}>0.94\right)$. The $\mathrm{Q}_{10}$ for $\mathrm{P}_{\text {net }}$ and $\mathrm{R}_{\text {dark }}$ at temperature $\mathrm{T}$ was determined as the calculated carbon exchange rate at $\mathrm{T}+5{ }^{\circ} \mathrm{C}$ divided by that at $\mathrm{T}-5^{\circ} \mathrm{C}$ (van Iersel and Lindstrom, 1999).

The experimental design for the temperature response curves was a randomized complete block (RCB) with two replications and two experimental treatments (the cultivars). Although the main objective of the experiment was to study environmental effects on the $\mathrm{CO}_{2}$ exchange rate of angelonia, this design also allowed for some comparisons between the two cultivars, by comparing the regression parameters using analysis of variance (ANOVA).

The experimental design for the light response curves was a RCB with four replications and the same two cultivars. Light response curves of leaf $\mathrm{P}_{\text {net }}$ were analyzed using quadratic regression: Leaf $\mathrm{P}_{\text {net }}$ $=\mathrm{a}+\mathrm{b} \times P P F+\mathrm{c} \times P P F^{2}$, where $\mathrm{a}=\mathrm{R}_{\text {dark }}\left(\mu \mathrm{mol} \cdot \mathrm{m}^{-2} \cdot \mathrm{s}^{-1}\right), \mathrm{b}=$ quantum yield (the slope of the $\mathrm{P}_{\text {net }}$-light response curves at a $P P F$ of 0 $\mu \mathrm{mol} \cdot \mathrm{m}^{-2} \cdot \mathrm{s}^{-1}$, in $\left.\mathrm{mol} \cdot \mathrm{mol}^{-1}\right)$, and $\mathrm{c}\left(\mathrm{m}^{2} \cdot \mathrm{s}^{-1} \cdot \mu \mathrm{mol}^{-1}\right)$ determines the curvature of the regression curve. The light compensation point was determined as the $P P F$ at which $\mathrm{P}_{\text {net }}$ equaled zero, as predicted by the regression curves. $P_{\text {net }}$ per unit leaf area was used to analyze light response curves to assure that quantum yield had interpretable units (moles of $\mathrm{CO}_{2}$ fixed per mole of incident $P P F$ ). Cultivar comparisons were made with ANOVA of the regression parameters.

\section{Results and Discussion}

Similar trends were seen in $\mathrm{P}_{\text {net }}$ of both cultivars of angelonia (Fig. 1) as temperature increased. $P_{\text {net }}$ of 'AngelMist Purple Stripe' was consistently higher than that of 'AngelMist Deep Plum', both on a whole plant (Fig. 1A) and on a leaf area basis (Fig. 1B). However, the only statistically significant differences occurred at temperatures from 20 to $28^{\circ} \mathrm{C}$. Maximum photosynthetic rate for 'AngelMist Purple Stripe' was $0.74 \mu \mathrm{mol} \cdot \mathrm{s}^{-1}$ (per five plants) at a temperature of $20.8^{\circ} \mathrm{C}\left(\mathrm{Q}_{10}=1\right.$, Fig. 2), while 'AngelMist Deep Plum' showed a maximum photosynthetic rate $\left(0.54 \mu \mathrm{mol} \cdot \mathrm{s}^{-1}\right.$ per five plants) at $19.8^{\circ} \mathrm{C}$. The optimal range for photosynthesis was similar for both cultivars, 18 to $22^{\circ} \mathrm{C}$ for 'AngelMist Deep Plum' and 19 to $23^{\circ} \mathrm{C}$ for 'AngelMist Purple Stripe'. $P_{\text {net }}$ of both cultivars decreased rapidly at superoptimal temperatures and was only $\approx 15 \%$ of the maximum $\mathrm{P}_{\text {net }}$ at an air temperature of $40{ }^{\circ} \mathrm{C}$. We have found no published information on $\mathrm{CO}_{2}$ exchange rates of angelonia. Armitage et al. (1981) measured leaf $\mathrm{P}_{\text {net }}$ of geranium (Pelargonium (hortorum L.H. Bail.) and showed that it had an optimum temperature range of 20 to $32^{\circ} \mathrm{C}$. In contrast, Welander and Hellgren (1988) showed that increasing temperature from 18 to $24^{\circ} \mathrm{C}$ decreased whole plant $\mathrm{P}_{\text {net }}$ of geranium, but their data were collected at very low $P P F$ levels ( 30 to $150 \mu \mathrm{mol} \cdot \mathrm{m}^{-2} \cdot \mathrm{s}^{-1}$ ). The decrease in $\mathrm{P}_{\text {net }}$ at high temperatures may have been caused by several factors: a decrease in gross photosynthesis, an increase in photorespiration, an increase in respiration other than photorespiration, feedback inhibition of photosynthesis after a long period of light exposure, or stomatal closure in response to increasing vapor pressure deficit at higher temperatures (Janoudi et al., 1993; Jiao and Grodzinski, 1996; van Iersel and Lindstrom, 1999). It is important to realize that the optimal temperature for $\mathrm{P}_{\text {net }}$ depends on the temperature at which plants are grown. In general, the optimal temperature for plants grown at high temperatures is higher than that of plants grown at cool temperatures (Björkman et al., 1980).

The $\mathrm{Q}_{10}$ for $\mathrm{P}_{\text {net }}$ decreased from $\approx 1$ at $21{ }^{\circ} \mathrm{C}$ to 0.3 at $36{ }^{\circ} \mathrm{C}$. Southern magnolia (Magnolia grandiflora $\mathrm{L}$.) has a similar decrease in $\mathrm{Q}_{10}$ for $\mathrm{P}_{\text {net }}$ with increasing temperature (van Iersel and Lindstrom, 1999). Since a $Q_{10}$ close to 1 indicates little response to temperature, this decrease in $\mathrm{Q}_{10}$ indicates that the relative decrease in $\mathrm{P}_{\text {net }}$ is faster as temperature increases. The small increase in $\mathrm{Q}_{10}$ from 34 to $36^{\circ} \mathrm{C}$ probably is an artifact of the third order polynomials fitted to the $P_{\text {net }}$ data, which suggest that $P_{\text {net }}$ no longer decreases at temperatures over $\approx 39^{\circ} \mathrm{C}$.

Dark respiration of both cultivars increased linearly with increasing temperature (Fig. 3) and 'AngelMist Purple Stripe' generally had a higher $\mathrm{R}_{\text {dark }}$ than 'AngelMist Deep Plum'. Differences in $\mathrm{R}_{\text {dark }}$ were only statistically significant (at temperatures $>20^{\circ} \mathrm{C}$ ) when the data were expressed on a whole plant basis, not when expressed per unit leaf area. The absolute increase in $\mathrm{R}_{\text {dark }}$ of the two cultivars with increasing temperature (i.e., the slope of the regression lines) also differed when the data were expressed on a whole plant basis $(P<$ 0.10 ), but not when expressed per unit leaf area.

The $\mathrm{Q}_{10}$ for $\mathrm{R}_{\text {dark }}$ of both cultivars decreased with increasing temperatures (Fig. 4), and was higher for 'AngelMist Purple Stripe' than for 'AngelMist Deep Plum', irrespective of temperature $(P<$ 0.05). 'AngelMist Purple Stripe' had a maximum $Q_{10}$ of 2.3 at $18^{\circ} \mathrm{C}$, while 'AngelMist Deep Plum' had a maximum $\mathrm{Q}_{10}$ of 2.07. In an extensive literature survey, Larigauderie and Körner (1995) found that $\approx 40 \%$ of all surveyed species had $Q_{10}$ values for $R_{\text {dark }}$ within the range of 2 to 2.5 , with an average $Q_{10}$ of 2.3. The decrease in $Q_{10}$ with
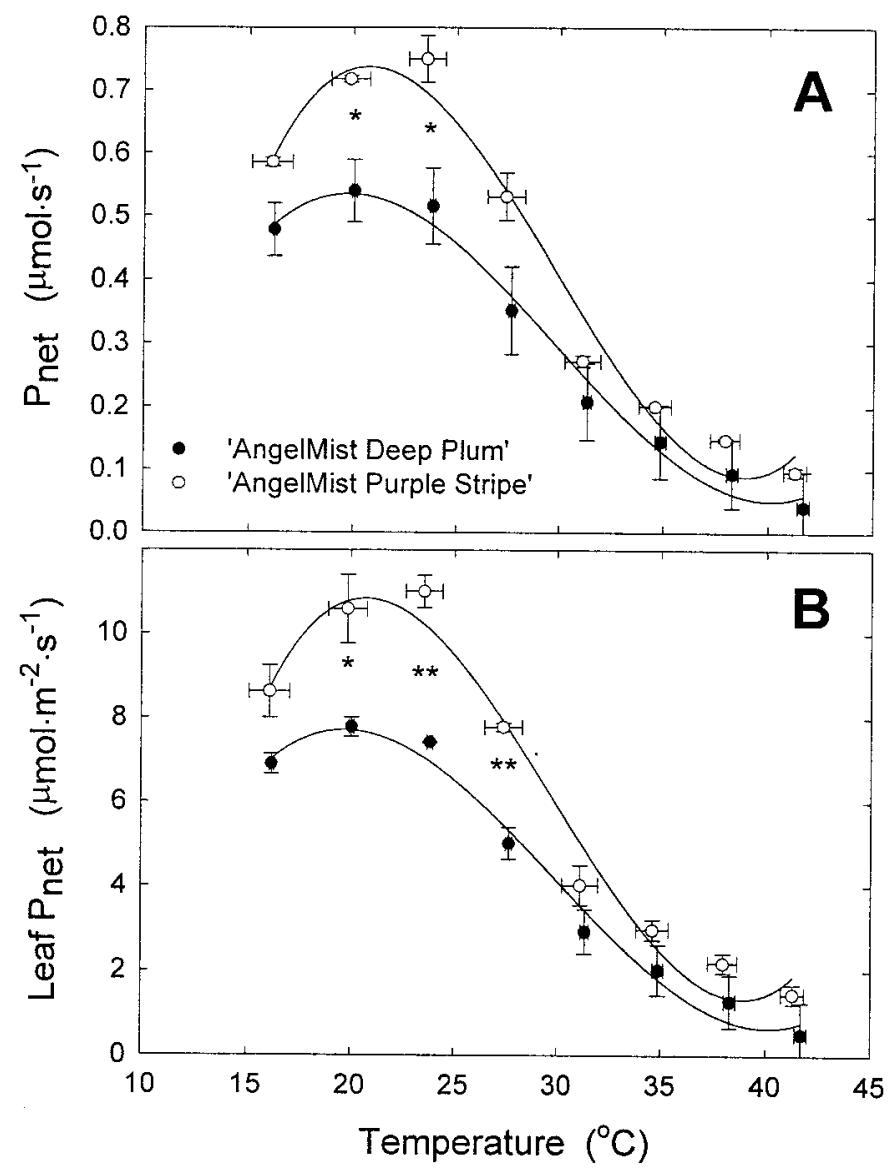

Fig. 1. Temperature $(\mathrm{T})$ effects on net photosynthesis $\left(\mathrm{P}_{\text {net }}\right)$ of two angelonia cultivars (means $\pm \mathrm{SE}$ ). Net photosynthesis of whole plants was measured at eight different temperatures during a 24-h period. Data are expressed as (A) total $\mathrm{CO}_{2}$ exchange rate of five whole plants ('AngelMist Deep Plum': $\mathrm{P}_{\text {net }}=-1.71+0.272$ $\times \mathrm{T}-0.0103 \times \mathrm{T}^{2}+1.15 \times 10^{-4} \times \mathrm{T}^{3}$; 'AngelMist Purple Stripe': $\mathrm{P}_{\mathrm{net}}=-3.70+0.521$ $\left.\times \mathrm{T}-0.0193 \times \mathrm{T}^{2}+2.16 \times 10^{-4} \times \mathrm{T}^{3}\right)$ and $(\mathbf{B})$ per unit leaf area ('AngelMist Deep Plum': Leaf $\mathrm{P}_{\text {net }}=-24.6+3.93 \times \mathrm{T}-0.149 \times \mathrm{T}^{2}+1.66 \times 10^{-3} \times \mathrm{T}^{3} ;$ 'AngelMist Purple Stripe': Leaf $\mathrm{P}_{\text {net }}=-54.0+7.62 \times \mathrm{T}-0.282 \times \mathrm{T}^{2}+3.16 \times 10^{-3} \times \mathrm{T}^{3}$ ). SE bars not shown are within the limits of the symbol. ****Significant differences between the cultivars at $P=0.10$ or 0.05 , respectively. 


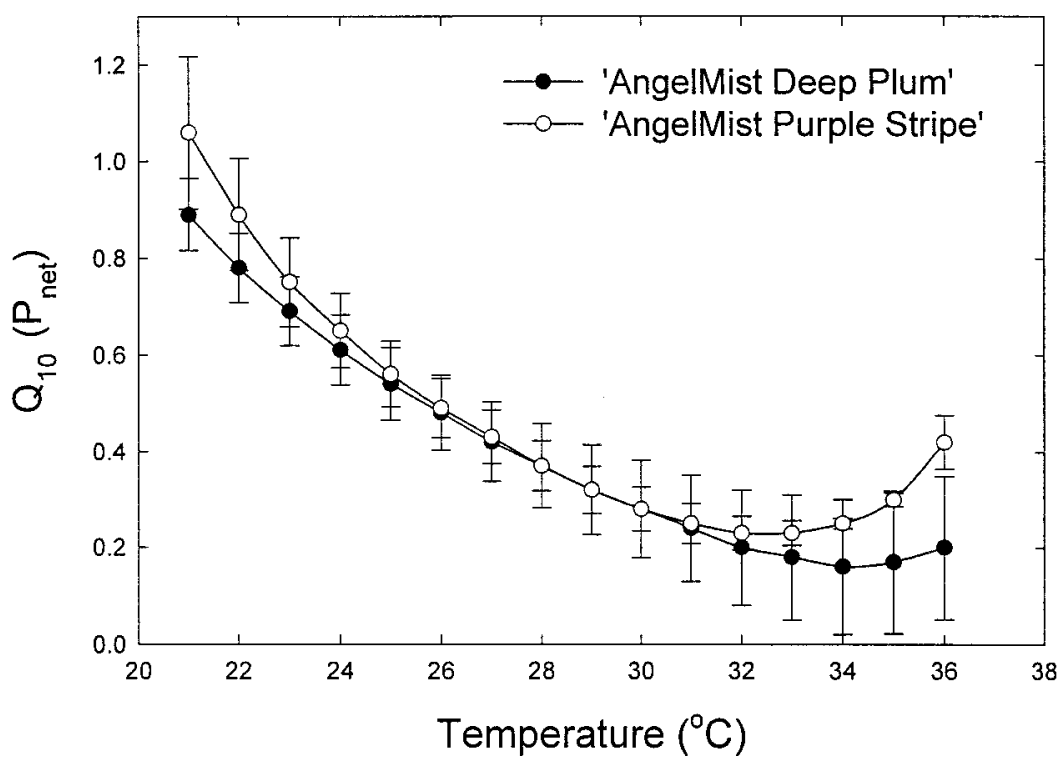

Larigauderie and Körner, 1995) and indicates an exponential increase in $\mathrm{R}_{\mathrm{dark}}$ with increasing temperature. However, an exponential curve did not fit our data nearly as well $\left(0.85<R^{2}<0.90\right)$ as a straight line $\left(R^{2}>\right.$ $0.94)$. A decrease in $\mathrm{Q}_{10}$ with increasing temperature is consistent with reports of Ranney and Peet (1994), who also found a linear increase in $\mathrm{R}_{\text {dark }}$ of birch (Betula $\mathrm{L}$. sp.) with increasing temperature, and Leonardos et al. (1994), who reported a small decrease in $\mathrm{Q}_{10}$ of Alstroemeria L. with increasing temperature. The response of $\mathrm{R}_{\text {dark }}$ to temperature depends on the growing conditions (Larigauderie and Körner, 1995) and both $\mathrm{R}_{\text {dark }}$ and the associated $\mathrm{Q}_{10}$ values of these angelonia cultivars likely would be different for plants grown under different conditions.

There was a strong quadratic correlation between $P P F$ level and $\mathrm{P}_{\text {net }}$ for both cultivars $\left(R^{2}>0.99\right.$, Fig. 5). Net photosynthesis of 'AngelMist Purple Stripe' generally was higher than that of 'AngelMist Deep Plum'. This difference was statistically significant at $P P F$ levels $>210 \mu \mathrm{mol} \cdot \mathrm{m}^{-2} \cdot \mathrm{s}^{-1}(P<0.025)$. Neither cultivar

Fig. 2. $\mathrm{Q}_{10}$ for net photosynthesis $\left(\mathrm{P}_{\text {net }}\right)$ of two angelonia cultivars at different temperatures $(\mathrm{T})$ (means $\pm \mathrm{SE}$ ). $\mathrm{Q}_{10}$-values were calculated as the estimated $\mathrm{P}_{\mathrm{net}}$ at $\mathrm{T}+5^{\circ} \mathrm{C}$ divided by that at $\mathrm{T}-5^{\circ} \mathrm{C}$. There were no differences between the $\mathrm{Q}_{10^{-}}$-values of the two cultivars. SE bars not shown are within the limits of the symbol.

increasing temperature is the result of the linear correlation between $\mathrm{R}_{\mathrm{dark}}$ and temperature. A constant $\mathrm{Q}_{10}$ is more common for $\mathrm{R}_{\text {dark }}$ (e.g.,

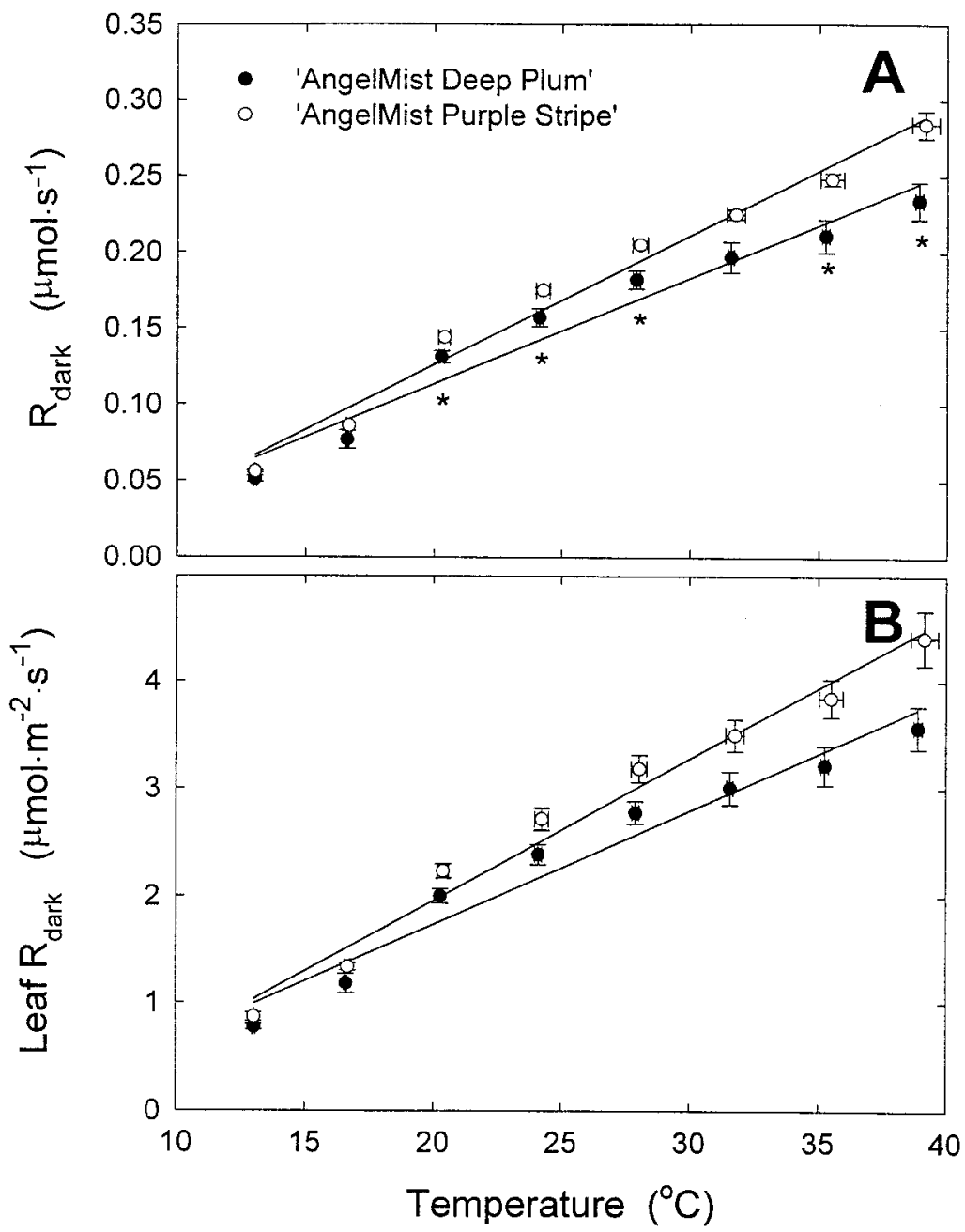
reached $P P F$ saturation at the highest $P P F$ level that could be reached in the growth chambers $\left(600 \mu \mathrm{mol} \cdot \mathrm{m}^{-2} \cdot \mathrm{s}^{-1}\right)$. The light compensation point of 'AngelMist Purple Stripe' $\left(67 \mu \mathrm{mol} \cdot \mathrm{m}^{-2} \cdot \mathrm{s}^{-1}\right)$ tended to be lower than that of 'AngelMist Deep Plum' (86 $\left.\mu \mathrm{mol} \cdot \mathrm{m}^{-2} \cdot \mathrm{s}^{-1}\right)(P=0.06)$. These light compensation points are within the normal range for plants. Poinsettias (Euphorbia pulcherrima Willd. ex Klotzsch) have a light compensation point between 31 to $51 \mu \mathrm{mol} \cdot \mathrm{m}^{-2} \cdot \mathrm{s}^{-1}$ (Nell and Barrett, 1986), while various vegetables have light compensation points between 32 to $86 \mu \mathrm{mol} \cdot \mathrm{m}^{-2} \cdot \mathrm{s}^{-1}$ (Nederhoff and Vegter, 1994). Dark respiration $\left(\mathrm{P}_{\mathrm{net}}\right.$ at a $P P F$ of $\left.0 \mu \mathrm{mol} \cdot \mathrm{m}^{-2} \cdot \mathrm{s}^{-1}\right)$ of the cultivars did not differ from each other.

Quantum yield (moles of $\mathrm{CO}_{2}$ fixed per mole of incident photons) is a measure of the maximum efficiency with which plants can use light to fix $\mathrm{CO}_{2}$ and can be determined as the slope of $\mathrm{P}_{\text {net }}-P P F$ curves at a $P P F$ of zero (e.g., Luo et al., 2000). The quantum yield of 'AngelMist Purple Stripe' $\left(0.038 \mathrm{~mol} \cdot \mathrm{mol}^{-1}\right)$ was significantly $(P=0.004)$ greater than that of 'AngelMist Deep Plum' $\left(0.026 \mathrm{~mol} \cdot \mathrm{mol}^{-1}\right)$, indicating that 'AngelMist Purple Stripe' is more efficient in using light energy to fix $\mathrm{CO}_{2}$ than 'AngelMist Deep Plum'. These quantum yields are similar to those reported by Luo et al. (2000), who found that quantum yield (also based on $\mathrm{P}_{\text {net- }}$ $P P F$ response curves of whole canopies) of sunflower (Helianthus annuus L.) was dependent on the leaf area index (leaf area per unit ground area). At a leaf area index of 0.5 (similar to the leaf area index of the angelonia in our study), they calculated a quantum yield of $0.034 \mathrm{~mol} \cdot \mathrm{mol}^{-1}$. It is important to note that Luo et al. (2000) and we calculated quantum yield based on incident $P P F$, not absorbed $P P F$ as is sometimes done. If quantum yield is based on absorbed $P P F$, it would be considerably higher, since our plants did

Fig. 3. Temperature $(\mathrm{T})$ effects on dark respiration $\left(\mathrm{R}_{\text {darr }}\right)$ of two angelonia cultivars. $R_{\text {dark }}$ was measured at eight different temperatures during a 24$\mathrm{h}$ period. Data are expressed as (A) total $\mathrm{CO}_{2}$ exchange rate of five whole plants ('AngelMist DeepPlum': $\mathrm{R}_{\text {dark }}=-0.0258+6.97 \cdot 10^{-3} \times \mathrm{T}$; 'AngelMist Purple Stripe': $\left.\mathrm{R}_{\mathrm{dark}}=-0.0440+8.50 \times 10^{-3} \times \mathrm{T}\right)$ and $(\mathbf{B})$ per unit leaf area ('AngelMist Deep Plum': Leaf $\mathrm{R}_{\text {dark }}=-0.392+0.106 \times \mathrm{T}$; 'AngelMist 0 Purple Stripe': Leaf $\mathrm{R}_{\text {dark }}=-0.688+0.132 \times \mathrm{T}$ ). There were no significant differences between the slopes of the regression lines for the two cultivars. "Significant differences between the cultivars at $P=0.10$. 


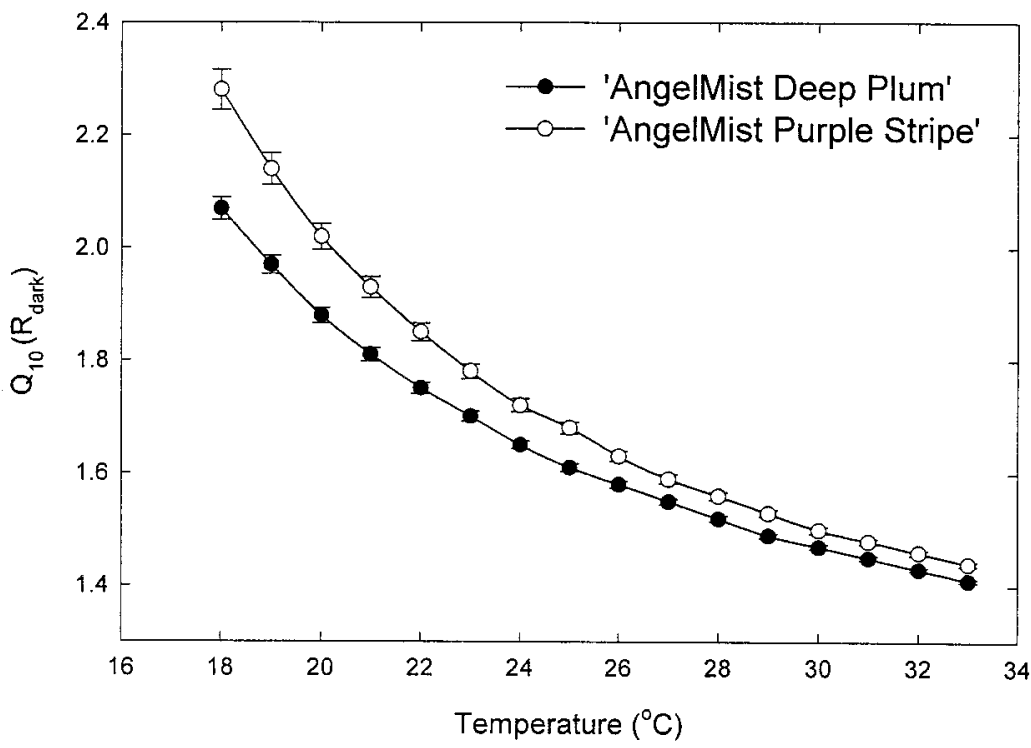

data with quantum yields based on leaf $\mathrm{P}_{\text {net }}$ are not particularly meaningful.

In conclusion, our data indicate that both cultivars of angelonia respond in a similar manner to increasing $P P F$ and temperature. $\mathrm{P}_{\text {net }}$ of both cultivars decreased when temperature increased above 20 to $21^{\circ} \mathrm{C} . \mathrm{P}_{\text {net }}$ increased with increasing $P P F$, and did not reach saturation at 600 $\mu \mathrm{mol} \cdot \mathrm{m}^{-2} \cdot \mathrm{s}^{-1}$. 'AngelMist Purple Stripe' had a higher $\mathrm{P}_{\text {net }}$ at $P P F$ levels $>210 \mu \mathrm{mol} \cdot \mathrm{m}^{-2} \cdot \mathrm{s}^{-1}$ than 'AngelMist Deep Plum', possibly because of a higher quantum yield. This may explain our observation that 'AngelMist Purple Stripe' generally is a faster growing cultivar than 'AngelMist Deep Plum' (unpublished results). Based on our findings, optimal growing conditions for angelonia are temperatures from 18 to $23^{\circ} \mathrm{C}$, with high irradiances.

\section{Literature Cited}

Armitage, A.M., W.H. Carlson, and J.A. Flore. 1981. The effect of temperature and quantum flux density on the morphology, physiology, and flowering of hybrid geraniums. J. Amer. Soc. Hort. Sci. 106:643-647.

Björkman, O., M.R. Badger, and P.A. Armond. 1980. Response and adaptation of

Fig. 4. $\mathrm{Q}_{10}$ for dark respiration $\left(\mathrm{R}_{\mathrm{dark}}\right)$ of two angelonia cultivars at different

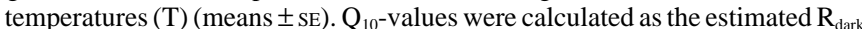
at $\mathrm{T}+5^{\circ} \mathrm{C}$ divided by that at $\mathrm{T}-5^{\circ} \mathrm{C}$. 'AngelMist Purple Stripe' consistently had a higher $\mathrm{Q}_{10}$ than 'AngelMist Deep Plum' $(P<0.05)$. SE bars not shown are within the limits of the symbol.

not absorb all incident light. Also, quantum yield determined from leaf $\mathrm{P}_{\text {net }}$ measurements is likely to be higher than those reported by Luo et al. (2000) and us, since a very high fraction of incident $P P F$ in absorbed when measuring leaf $\mathrm{P}_{\text {net }}$. Therefore, comparisons of our

Fig. 5. Effect of photosynthetic photon flux $(P P F)$ on net leaf photosynthesis $\left(\mathrm{P}_{\text {net }}\right)$ of two angelonia cultivars (means $\pm \mathrm{sE}$ ). Although $\mathrm{P}_{\text {net }}$ of whole plants was measured, data are expressed per unit leaf area. Differences between the cultivars were statistically significant at $P P F$ levels $>210 \mu \mathrm{mol} \cdot \mathrm{m}^{-2} \cdot \mathrm{s}^{-1}(P<$ 0.025). The lines represent quadratic regression curves ('AngelMist Deep Plum': Leaf $\mathrm{P}_{\text {net }}=-2.22+25.7 \times 10^{-3} \times P P F-1.34 \cdot 10^{-5} \cdot P P F^{2}$; 'AngelMist Purple Stripe': Leaf $\mathrm{P}_{\text {net }}=-2.53+38.4 \times 10^{-3} \times P P F-2.23 \cdot 10^{-5} \cdot P P F^{2}$ ), which were used to determine dark respiration, quantum yield, and the light compensation point. se bars not shown are within the limits of the symbol.

photosynthesis to high temperatures, p. 233-249. In: N.C. Turner and P.J. Kramer (eds.) Adaptation of plants to water and high temperature stress. Wiley, New York.

Elmore, C.D. 1980. The paradox of no correlation between leaf photosynthetic rates and crop yields, p. 155-167. In: J.D. Hesketh and J.W. Jones (eds.). Predicting photosynthesis for ecosystem models. vol. II. CRC Press, Inc., Boca Raton, Fla.

Evans, L.T. 1993. Crop evolution, adaptation and yield. Cambridge Univ. Press, Cambridge, United Kingdom.

Janoudi, A.K., I.E. Widders, and J.A. Flore. 1993. Water deficits and environmental factors affect photosynthesis in leaves of cucumber (Cucumis sativus). J. Amer. Soc. Hort. Sci. 118:366-370. on export of sugars during steady-state photosynthesis in Salvia splendens. Plant Physiol. 111:169-178.

Larigauderie, A. and C Körner. 1995. Acclimation of leaf dark respiration to temperature in alpine and lowland species. Ann Bot. 76:245-252.

Lawson, R.H. and M.S. Roh. 1995. New crops in the U.S.A. Acta Hort. 397:31-40.

Leonardos, E.D., M.J. Tsujita, and B. Grodzinski. 1994. Net carbon exchange rates and predicted growth patterns in Alstroemeria 'Jacqueline' at varying irradiances, carbon dioxide concentrations, and air temperatures. J. Amer. Soc. Hort. Sci. 119:1265-1275.

Long, S.P, P.K. Farage, and R.L. Garcia. 1996. Measurement of leaf canopy and photosynthetic $\mathrm{CO}_{2}$ exchange in the field. J. Expt. Bot. 47:1629-1642.

Luo, Y., D. Hui, W. Cheng, J.S. Coleman, D.W. Johnson, and D.A. Sims. 2000. Canopy quantum yield in a mesocosm study. Agr. For. Meteorol. 100:35-48.
Jiao, J. and B. Grodzinski. 1996. The effect of leaf temperature and photorespiratory conditions

Nederhoff, E.M., and J.G. Vegter. 1994. Photosynthesis of stands of tomato, cucumber, and sweet pepper measured in greenhouse undervarious $\mathrm{CO}_{2}$ concentrations. Ann. Bot. 73:353361.

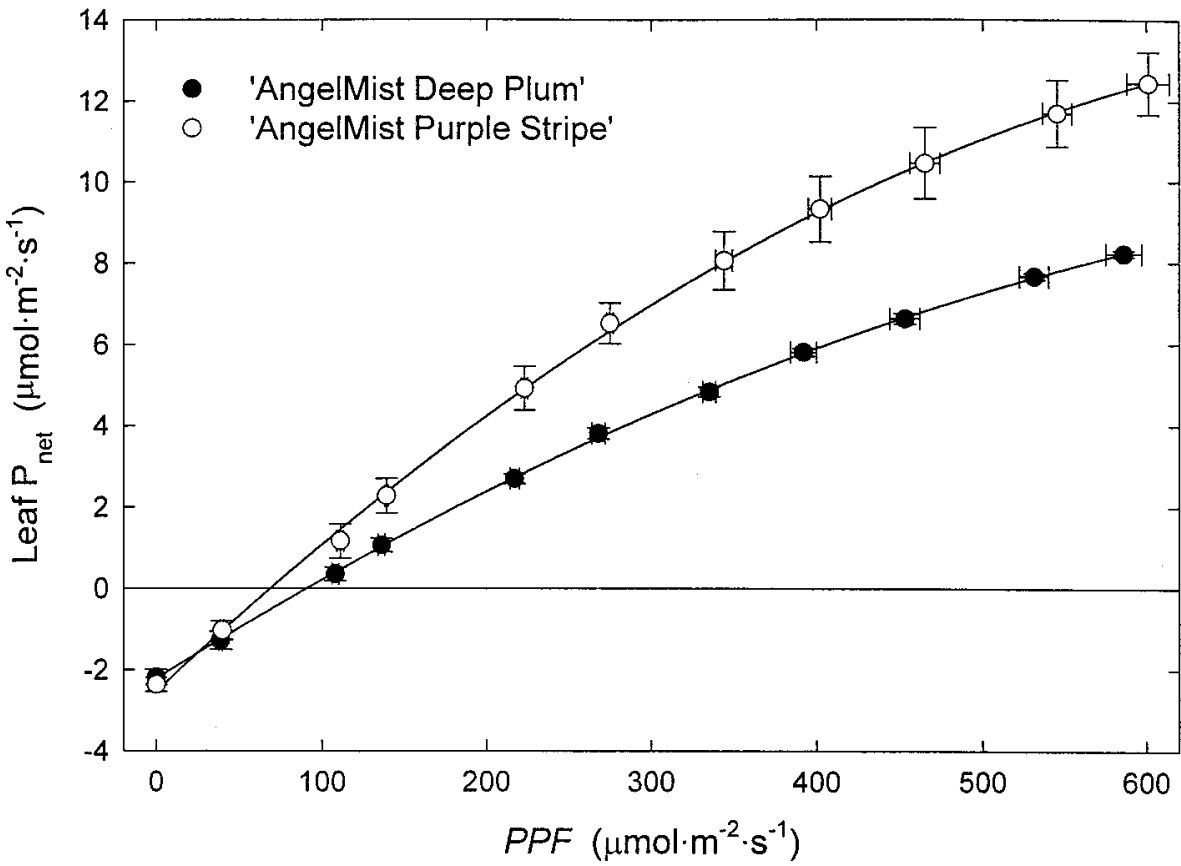

Nell, T.A. and J.E. Barrett. 1986. Production light level effect on light compensation point, carbon exchange rate and postproduction longevity of poinsettias. Acta Hort. 181:257-262. Noordegraaf, C.V. 1998. Trends and requirements in floriculture in Europe. Acta Hort. 454: 39-44.

Ranney, T.G. and M.M. Peet. 1994. Heat tolerance of five taxa of birch (Betula): Physiological responses to supraoptimal leaf temperatures. J. Amer. Soc. Hort. Sci. 119:243-248. Ranney, T.G. and J.M. Ruter. 1997. Foliar heat tolerance of three holly species (Ilex spp.): responses of chlorophyll fluorescence and leaf gas exchange to supraoptimal leaf temperatures. J. Amer. Soc. Hort. Sci. 122:499-503.

Smart, D., A. Ferro, K. Ritchie, and B. Bugbee. 1995. On the use of antibiotics to reduce rhizoplane microbial populations in root physiology and ecology investigations. Physiol. Plant. 95:533540.

van Iersel, M.W. and B. Bugbee. 2000. A semi-continuous, multi-chamber crop $\mathrm{CO}_{2}$ exchange system: Design, calibration, and data interpretation. J. Amer. Soc. Hort. Sci 125:86-92. van Iersel, M.W. and O.M. Lindstrom. 1999. Temperature response of whole-plant $\mathrm{CO}_{2}$ exchange rates of three magnolia cultivars. J. Amer. Soc. Hort. Sci. 124:277-282.

Welander, N.T. and O. Hellgren. 1988. Growth, development, net photosynthesis and dark respiration in Pelargonium $\times$ hortorum $\mathrm{cv}$. Celeste in relation to temperature, quantum flux density and absorbed quanta. J. Hort. Sci. 63:659-666. 